\title{
Review Article \\ Scientific and Engineering Literature Mini Review of Molten Salt Oxidation for Radioactive Waste Treatment and Organic Compound Gasification as well as Spent Salt Treatment
}

\author{
Petr Kovařík, ${ }^{1}$ James D. Navratil, $^{2}$ and Jan John ${ }^{1}$ \\ ${ }^{1}$ Faculty of Nuclear Sciences and Physical Engineering, Czech Technical University in Prague, 11519 Prague 1, Czech Republic \\ ${ }^{2}$ Hazen Research Inc., Golden, CO 80403, USA \\ Correspondence should be addressed to Petr Kovařík; petr.kovarik@envinet.cz
}

Received 28 October 2014; Accepted 31 December 2014

Academic Editor: Zhiwei Zhou

Copyright (C 2015 Petr Kovařík et al. This is an open access article distributed under the Creative Commons Attribution License, which permits unrestricted use, distribution, and reproduction in any medium, provided the original work is properly cited.

\begin{abstract}
Literature review was performed for the molten salt oxidation technology in order to collect all available scientific and engineering information for further use of this technology in nuclear applications. This report provides a summary of a review of scientific and engineering literature on MSO treatment of a wide variety of radioactive wastes, organic compound gasification, and related studies such as radioactive spent salt processing that was found important for further development of the MSO technology in the nuclear field for radioactive waste treatment. Miscellaneous nonnuclear uses of molten salts, such as converting carbon monoxide to carbon dioxide, are not discussed.
\end{abstract}

\section{Introduction and Background}

A variety of radioactive wastes that contain organic compounds are in storage around the world as well as at the Czech Nuclear Power Plants. These types of radioactive wastes can be difficult to treat, and complex and/or expensive systems are usually required to safely and effectively destroy the wastes. Conventional systems may not always be adequate for treatment. For example, the typical method for destruction of organic radioactive wastes is incineration, and this method has many drawbacks, including public acceptance. Thus, new nonthermal methods are needed that can provide high-destruction efficiencies with low capital and operating costs for the safe treatment of these types of "problematic" radioactive wastes.

Molten salt oxidation (MSO) is a nonthermal method that is ideal to safely and effectively destroy organic components of various wastes [1]. MSO has a long development history $[1,2]$. Over 50 years ago, Rockwell International first developed and tested a variety of molten salt systems from laboratory scale to pilot scale and some to production scale. Nitrate salts were used for heat transfer applications, carbonate salts for oxidation and reduction reactions, sulfate salt reduction for carbonate recycling, and chloride salts for pyrochemical partitioning. MSO processes were evaluated for carbon (coal) oxidation as well as destruction of propellants and other energetic wastes. New materials of construction for use with MSO systems were developed along with the above applications. A commercial scale test facility was permitted for testing components and processes. MSO has also been tested on both pilot plant and plant scale systems for destruction of a large variety of radioactive, hazardous, and reactive type wastes including explosives.

MSO operations for waste destruction generally consist of a system where solid and/or liquid wastes are injected into a bed of molten carbonate salt in the presence of an oxidizing gas. Oxidation of the organic compounds is catalyzed by the salt and complete destruction of the organics (typically $>99.9999 \%$ ) is achieved at temperatures of $800-1000^{\circ} \mathrm{C}$. The acid gases, such as hydrochloric acid, usually formed by halogenated organic wastes, are completely removed by the sodium carbonate pool and converted to the respective halide compound. No wet off-gas scrubbing system is needed (it has been used for off-gas treatment on other processes such as incineration). Thus, the by-product waste of the process consists of nonhazardous fused salt with no liquid effluents 
(unless there are hazardous and/or radioactive species in the feed). Another major advantage of MSO is that it is not considered an incineration process, and permitting and public acceptance issues are minimized compared with incineration processes; furthermore, no dioxins are generated in MSO as they are in incineration processes. MSO has also been used for off-gas treatment of a variety of processes.

Based on the above, the MSO is particularly attractive for processing of mixed waste (a mixture of hazardous and radioactive wastes). The organic components of the mixed waste are oxidized and are released as mainly carbon dioxide in the off-gas, and the radioactive species, such as rare earth fission products or actinide elements, are retained in the salt bath. Retention of $>99 \%$ has been reported for cesium, cobalt, chromium, europium, iodine, iron, lead, manganese, nickel, and ruthenium. These radioactive elements may be further recovered from the spent salt using standard chemical processes such as aqueous dissolution, solid-liquid separation, and ion exchange, all of which concentrate the radioactivity and render the salt as nonradioactive and nonhazardous; in most cases the salt can be recycled.

Experiments using MSO to destroy halogenated solvents, polychlorinated biphenyls, chemical warfare agents, combustible solids, uranium-contaminated solvents, plutoniumcontaminated solids, and other types of wastes have been reported in the literature along with applications to off-gas scrubbing. This report summarizes a review of scientific and engineering literature on MSO treatment of a wide variety of wastes, organic compound gasification, and related studies such as spent salt processing [1-122] that was found important for further development of the MSO technology in the nuclear field for radioactive waste treatment. Therefore, this paper contains only review of the most important scientific and engineering papers and literature that can be used for or are connected with the nuclear applications of the MSO. Miscellaneous uses of molten salts, such as converting carbon monoxide to carbon dioxide, will, therefore, not be discussed [81].

General reviews of the topic can be also found in other documents $[1,2,5,7,8,11,55,56,71,78-80,82,84,98,111$, $114,116,118,121]$. A recent review is especially noteworthy because of its comprehensiveness to a wide range of MSO topics [116]. Another report reviews the historical aspects, the advantages and disadvantages and general operation of MSO, and technology needs [7]; these assessments and reviews provide an excellent evaluation of MSO technology.

\section{Summary of MSO Equipment, Applications, and Salt Processing}

This major section contains a summary of papers on MSO equipment, studies on salt behavior, and applications of the treatment of a variety of wastes, salt processing, and encapsulation of wastes arising from MSO operations with focus to nuclear application. Even though there are described nonnuclear applications in several reported papers, the experience from these applications can be transferred to nuclear applications, that is, use of the MSO for radioactive waste treatment. All these applications, even though they are not directly nuclear, are very important for understanding of the MSO system behavior and setup.

There are just two references on MSO treatment of medical wastes $[5,82]$, and these are described in conjunction with the treatment of other wastes (chemical, hazardous, radioactive, and mixed); thus, discussion of these types of wastes will be presented in those respective sections.

2.1. Equipment and Studies on Salt Behavior. Many papers in the scientific and engineering literature on MSO describe complete systems and auxiliary equipment as part of papers in which the main subject is destruction of hazardous, radioactive, and/or mixed waste [5]. These kinds of papers are summarized below.

Typical MSO reactors have traditionally been constructed with an inner ceramic crucible and a stainless steel outer container. Corrosion and deposition of oxide films on ferrous alloys are usually considered in the selection of construction materials for MSO reactors [69]. Various downcomers (injection tubes) for feed and oxidizing gas (typically air or oxygen) have been used, and various improvements to the typical equipment have been made in the last 20 years $[5,15,21,22,28,29,53,61,69,70,76,83,105,113]$.

Most noteworthy is the development of new reactor systems, from a single reactor with one stage of reaction to two reactors, one primary for pyrolysis and one secondary to complete the oxidation of waste, and two reactors operating in series for waste treatment. A figure of all three types of reactors is in [116].

Lawrence Livermore National Laboratory (LLNL) developed the two-stage, two-vessel MSO system [5, 28]. The first stage operates under oxygen-deficient (pyrolysis) conditions and the second stage completes oxidation of the evolved gases. The purpose of the two-stage system was to process radioactive wastes that contain high concentrations of alumina-silicates in the form of soils or clays, or high concentrations of nitrates.

The above study was part of an integrated MSO demonstration program at LLNL to identify the most suitable types of wastes at LLNL for MSO treatment [26, 28, 32, 34]. Their MSO system consists of a feed preparation equipment, a novel MSO processor (as described above) with off-gas treatment, and a salt recycle system with equipment for ceramic waste encapsulation. In these reports, the equipment is described along with preliminary process data.

A variety of other improvements of MSO equipment has been reported $[21,22,61,94]$. One such improvement is a tall, thin vessel, where the liquid salt does not splash upward and plug the gas outlet [21]. Another improvement is an injector nozzle for safely injecting energetic materials into an MSO reactor [22]. Furthermore, an improved MSO delivery system was developed, which includes a feeder and injector, that allows solid waste to be more accurately and safely injected into the molten salt [61].

Other related improvements that are a part of an MSO reactor system include components such as catalysts. For example, the potential of an open-pore ceramic foam as 
a support for molten salt, diesel soot oxidation catalysts was reported [33].

Information about related, but improved, equipment that is applicable for MSO can also be found in the scientific and engineering literature. For example, a high temperature liquid injection apparatus has been developed [15]. Molten salt electrolysis systems, using ceramic membranes, could also have application to MSO equipment $[29,30]$.

The behavior of molten salts has also been studied. One such study involved the gas phase dispersion characteristics of air in a molten sodium carbonate system $[70,76]$; the effects of the gas velocity and molten salt temperature on the gas phase axial dispersion coefficient were determined. The implications of the uncertainty of thermal conductivity and viscosity of molten salts in the design of MSO equipment are also presented [62]; the reported results support the implementation that careful selection of experimental data is needed; otherwise, equipment will be either underor overdimensioned, with resultant increased capital costs and/or poor operation. The flow characteristics of air-molten carbonate were also studied [105].

2.2. Organic Compound Gasification. Gasification of coal was one of the first applications of MSO technology [1-3, 43]. Traditionally MSO gasification of organics used sodium carbonate heated above its melting point where the molten salt functions as a catalyst, fluid reacting bed, and heat transfer medium. The coal is flash-pyrolyzed such that no tars or oils are produced. Steam is usually injected into the molten salt along with pulverized coal to decompose the coal's higher organic molecules that catalytically assist the carbon-steam reactions to produce carbon monoxide and hydrogen gases at atmospheric pressures. At higher pressures, significant methane and higher hydrocarbons are produced. Hydrogen and carbon monoxide can be used as a fuel gas or in synthesis to produce virtually any organic material; methanol is commonly produced and can also be used as fuel or as raw material to produce various organics.

Coal gasification studies prior to 2009 are provided in a recent patent for converting coal and other fossil fuels to hydrogen [110]. In this patented process, the coal is reacted with water in a molten salt reactor at elevated temperatures in the presence of magnesium silicate. The magnesium silicate reacts with the carbon dioxide, yielding hydrogen as the sole product gas.

Waste paper gasification to produce carbon monoxide using molten potassium, sodium, and/or lithium carbonates in an atmosphere of carbon dioxide was reported [77]. The experimental results reported demonstrate that the intermixture carbonates exhibit an enhancement of catalytic activity compared with the individual carbonate salt. The reaction rate depended on temperature.

Another system was reported for gasification of sludge and organic waste using molten salt [89]. A molten salt mixture of lithium and potassium carbonates was used to generate carbon monoxide and hydrogen from rice (a surrogate of an organic waste) using carbon dioxide as the oxidizing gas. The process generates carbon monoxide and hydrogen near the chemical equilibrium value, but sulfur produced in the process was not completely fixed in the molten salt. Because rice is lighter than the carbonate and floated on top of the molten salt, the rice was not completely converted to carbon monoxide and hydrogen. Lengthening the contact time between the rice and the molten salt was suggested to eliminate these problems.

2.3. Waste Treatment. This section summarizes key papers dealing with hazardous, radioactive, and mixed solids wastes. Other papers will be referenced but not discussed. Many of the papers report MSO work on treating one or more of these types of wastes. In these cases, the paper will only be referenced in the first section in which the paper is discussed.

\subsection{General, Chemical, and Hazardous Waste Treatment.} Many scientific papers report the MSO destruction of chemical and hazardous wastes as well as radioactive and mixed wastes $[1,40,82,93]$. There are a few papers on general types of waste that are spiked and used as surrogates for hazardous or radioactive wastes $[13,18]$.

Two key papers discuss the advantages of MSO for treating organic waste (specifically tributyl phosphate) as well as the mechanism of the process $[52,82]$. The mechanism is claimed to be by the formation and consumption of peroxide and superoxide ions and not by the catalysis by carbonate. The addition of nitrate to the molten carbonate allows operation of the process at lower temperatures without the loss of destruction efficiency.

The above-referenced investigations were extended to the MSO treatment of tires [58, 82]. Devulcanization was first required for the complete oxidation of used automobile tires using a phosphorus compound. The scrap rubber was completely oxidized, leaving no carbon in the molten carbonate containing $5 \%$ nitrate. The off-gases were carbon dioxide, nitrogen, and water.

The destruction of chlorinated organic solvents in a molten carbonate in the presence of floating powdered transition metal oxides was also reported $[72,73,86]$. At a given oxidation efficiency, the addition of the transition metal oxides to the molten salt reduced the operating temperatures. The collection of chlorine by the molten carbonate was not influenced, which indicated that no acid gas scrubbing system was necessary in the process.

Oxidation of organic compounds such as carbon monoxide, carbon tetrachloride, chlorobenzene, and methane in various molten salt mixtures with catalysts was studied [31]. The effects of load and melt composition, oxygen concentration, and temperature on destruction efficiency were studied. The use of molten catalysts based on alkaline metal carbonates or vanadium oxide can be effectively used for the oxidation of the compounds listed above. Catalyst performance was found to relate to its composition and operation conditions, and transition metal oxides increased the efficiency of destruction.

MSO was also evaluated for the destruction of chlorobenzene $[56,67]$. The MSO reactor was laboratory scale. The favorable MSO results were compared with incineration, 
and the advantages and disadvantages of both processes are presented in the paper.

A halogenated solvent that consisted mostly of methyl chloroform was treated with a pilot-scale MSO system [59, $90,92,95,96]$. Eighty weight percent of the waste contained chlorine that with MSO treatment was captured as sodium chloride in the molten salt. When the spent salt was treated by aqueous methods, the sodium chloride leached chrome; thus, the solidified waste salt exhibited the toxicity characteristic for chrome. The operating ranges for the salt bed and off-gas temperatures, as well as the feed rate that enables sustained operation, were identified in these experiments. Maintenance requirements and processing capacity increased with feed rate.

Various solid waste organics were test-burned in a benchscale MSO system [64]. Hydrochloric acid, hydrofluoric acid, chlorine, and fluorine, released during the thermal decomposition of solids, were completely collected in the molten sodium carbonate. Sulfur dioxide emissions increased when rubber gloves were treated, but decreased with the stoichiometric air ratio. The entrainment of spiked metals increased with the operating temperature and chlorine content of the waste.

MSO destruction of polyvinylchloride plastics spiked with cadmium, cerium, cesium, chromium, gadolinium, lead, and samarium was evaluated as a function of temperature and sodium chloride content in the molten sodium carbonate [66]. The impact of temperature on cadmium and lead retention in molten carbonate was small, but higher with increased sodium chloride in the melt. Neither temperature increase nor chlorine accumulation in the MSO reactor reduced metal retention. The retention of cerium, chromium, gadolinium, and samarium was not affected by temperature increases or sodium chloride content.

Another paper examined the decomposition of polychlorobiphenyls in $\mathrm{n}$-nonane solution using molten sodium or potassium carbonate and hydroxides at $500-700^{\circ} \mathrm{C}[100]$. The decomposition efficiency $>99.995 \%$ was obtained with increasing temperature.

This paper reports MSO research on the oxidation of cyanide ions by oxygen as a function of flow rate of the total gas mixture, input gas composition, melt composition, and temperature [35]. In the process, cyanide destruction proceeds rapidly and $\mathrm{CN}^{-}$and $\mathrm{CNO}^{-}$were the major components in the salt and $\mathrm{NO}_{2}{ }^{-}$and $\mathrm{NO}_{3}{ }^{-}$were the minor components. Carbon monoxide and nitrogen dioxide emissions were within the limits of air quality standards.

The destruction performance of a two-stage MSO reactor for ion exchange resins spiked with toxic metals and radioactive metal surrogates was reported [74]. In the primary MSO reactor, the destruction of the organics was highly efficient. Carbon monoxide from the primary reactor was completely oxidized in the secondary MSO reactor. Sulfur collection in the two-stage reactor system was highly efficient, and over 99.5\% of the cadmium, cesium, cobalt, lead, and strontium remained in the salt of the MSO reactor.

The above two-stage reactor system was also used for the destruction of chlorobenzene and trichloroethylene [90, 92, 95], as well as carbon tetrachloride [96]. Various oxidation organic by-products and hydrogen chloride were produced in the primary reactor but destroyed or collected in the secondary MSO reactor. The results show that an increase in the air rate did not increase the reaction rates significantly, but a small increase in the temperature reduced the emission of carbon monoxide.

MSO treatment of pulp mill liquors for separation of nonprocess chemicals and reclaiming plant chemicals for recycling was evaluated [50]. MSO process flow sheets are presented in this paper along with estimates of capital and operating costs.

Using an oxygen sparging method, precipitation of some rare earth chlorides in a mixed lithium and potassium chloride molten salt was reported [83]. Oxychlorides formed as a precipitate regardless of the oxygen sparging time and the molten salt temperature. Conversion of the rare earth chlorides into insoluble precipitates increased with the oxygen sparging time and the molten salt temperature.

Although not directly related to waste treatment, electrolysis in molten salts has been evaluated to recover various reactive metals [51, 57]. Recovery of calcium and cerium (as surrogates for actinides) from waste salts is discussed in this paper. Experimental data are given that show the value and limitations of the process reduction process to recover these metals. Another related paper discusses a new molten salt electrode oxidation processes along with descriptions of cell designs and mediated reactions [53].

2.5. Radioactive Waste Treatment. Summary reviews of radioactive waste treatment using MSO have appeared in the scientific literature $[18,80,87,98]$. One comprehensive paper, as mentioned above, has recently appeared [116]. Based on the author's scientific judgment, some specific papers on research work will not be described, but only referenced [25]; other papers, judged to be more important for the planned work at Rez on MSO radioactive waste treatment, are summarized below.

An example of some recent MSO work at Oak Ridge National Laboratory involves the destruction of an intermediate level radioactive waste stream [10]. The waste was a slurry of concentrated sodium hydroxide and sodium nitrate containing ion exchange resins, kerosene, polyvinylchloride, and tributyl phosphate. The results of the feasibility tests showed complete destruction of the organic components with no release of hazardous gases.

A study was described above in the equipment section concerning an integrated MSO demonstration program at LLNL to identify the most suitable types of waste for MSO treatment at LLNL $[26,28,32,34]$. Further work was reported using the system for treatment of a variety of hazardous wastes [37, 38, 44, 45]. The program's MSO system was also successfully tested for the destruction of explosives, with and without activated charcoal and sludge $[5,65,119]$.

MSO and aqueous chemical separation were examined at Los Alamos National Laboratory (LANL) to process combustible waste containing plutonium-238 to recover the plutonium-238 from the waste stream and allow licensed disposal of the residual waste [36, 39]; a conceptual design of the waste treatment technology is described in this paper. 
Several other similar studies were reported using MSO to recover plutonium-239 from a variety of other waste materials [42, 47, 48, 68, 75].

The treatment of spent nuclear fuels using catalyzed MSO has been reported [98]. The process uses molten chlorides instead of carbonates and is claimed to be a fast and efficient technique to reprocess nuclear fuel and concentrate fission products and nuclear waste.

Optimum operating conditions of an MSO system were determined based on the characteristics of hazardous gas emissions [113]. The destructive testing used spent cationic ion exchange resins containing radioactive isotopes of cesium, cobalt, and strontium. Optimum conditions for organic resin destruction were an excess air ratio of $100-$ $150 \%$ and a reactor temperature of $850-900^{\circ} \mathrm{C}$, respectively. A further increase in the reactor temperature resulted in a greater emission of cesium species.

Electrolysis has also been evaluated to treat radioactive waste salts for the recovery of lithium [49]; based on the experimental results, lithium oxide is reduced to lithium and separated from cesium and strontium oxides by controlling the applied potential and the lithium chloride concentration.

Similar studies have been reported by other researchers $[99,109]$. For example, four techniques for the extraction of lanthanide elements from molten salts during reprocessing of nuclear wastes are described in this paper [109]. One technique is the precipitation of insoluble lanthanide oxides or oxyfluorides. The other techniques use electrochemistry in molten fluorides for extraction and process control. Of the techniques, electrodeposition of lanthanides in the form of alloys was reported to be the most promising method.

2.6. Mixed Waste Treatment. As mentioned above, papers that discussed mixed waste were included in the sections on chemical/hazardous or radioactive wastes if the papers contained work on both types of wastes. The papers below pertain to papers that discussed work solely with mixed wastes.

General reviews of MSO treatment of mixed wastes (hazardous and radioactive) can be found in the scientific and engineering literature [17]; one recent and comprehensive review paper appeared in the literature [116]. Some specific examples of MSO research and development for mixed waste treatment are summarized below.

A pilot-scale MSO system was used to process a mixed waste consisting mostly of methyl chloroform [120]. During processing, the chlorine gas produced was captured as sodium chloride in the molten salt. The operating ranges for the salt bed temperature, off-gas temperature, and feed rate that enable sustained operation were identified. At feed rates below the sustainable limit, both processing capacity and maintenance requirements increased with feed rate.

Other research involved the destruction of mixed organic wastes in a fluidized molten salt catalyst bed [30].

2.7. Spent Salt Processing and Encapsulation. A general method of spent salt processing is that the spent salt is first contacted with water to dissolve the soluble salts, mainly sodium chloride and residual sodium carbonate [12]. The solution is sometimes passed through an ion exchange column to recover valuable anions such as uranium [27]. A precipitation method has been patented for uranium and thorium recovery from spent MSO salts [60]. Other methods have been used to recover plutonium [47]. Fractional crystallization of the solution, either skipping the separation step or used following the separation step, allows the sodium carbonate to be separated from sodium chloride for recovery and reuse of the carbonate. Insoluble waste or ash, first filtered from the solution, is treated as dictated by the composition of the residue. In most cases the residue must be encapsulated prior to disposal.

One recent report describes an improved technique of salt processing [23]. The process uses salt dissolution, $\mathrm{pH}$ adjustment, chemical reduction (using dithionite and/or sulfiding) to reduce soluble metals in solution, filtration, ion exchange, and drying. The process has been demonstrated to effectively reduce the secondary waste to less than $5 \%$.

Related methods also have been reported that may be useful for MSO spent salt processing [20, 41, 103, 104]. For example, treatment of waste salts from electrorefining processes uses oxidative precipitation of the rare earth elements $[29,103,104]$. Separation of rare earth elements by oxidative precipitation in a lithium chloride-potassium chloride molten salt was tested without using precipitating agents [103]. Oxychlorides and oxides were formed as a precipitate by a reaction with oxygen. The conversion efficiencies of the rare earth elements to their molten saltinsoluble precipitates were increased with sparging time and temperature.

A variety of methods have also been used to make the residual waste containing hazardous or radioactive compounds pass certain disposal requirements [16, 19, 46, 97]. Methods to encapsulate the final residual waste from MSO processing include ceramic materials [16], polyethylene [19], and a silicon-alumina-phosphorous based material [97]. The use of oxides of silicon, alumina, and phosphorus gave higher disposal efficiencies and lower waste volumes compared with other immobilization methods [97]. A glass-zeolite ceramic waste form was developed at Argonne National Laboratory for the disposal of radioactive waste salts from electrometallurgical treatment of spent nuclear fuel; the results of characterization studies on the waste form are described in papers $[46,88,97]$.

A gel-route encapsulation method was developed using borosilicate glass as a chemical binder where silicate produces an amorphous phase and phosphates are encapsulated by the vitrified phase $[88,97]$. Cesium in the gel product is preferentially situated in the silicate phase, and it is vitrified into a glassy phase after heat treatment. The strontium phase contains mainly phosphate compounds and is encapsulated by the glassy phase. Leaching tests showed a high leach resistance for cesium and strontium. This paper also describes waste forms containing a molten salt. These studies and modifications of the results have been included in other papers [101-104, 106-108, 115]; some of these papers also describe related studies on modeling and pyroprocessing of MSO waste $[102,104,106,107]$. 
Zeolite 4A was used for the removal of cesium and strontium from molten lithium chloride [85]. In this study, the ion exchange characteristics of the zeolite in the molten salt were investigated. The results indicate that zeolite $4 \mathrm{~A}$ was a very effective molecular sieve for sorbing the cesium and strontium in the lithium chloride waste salt.

\section{Conflict of Interests}

The authors declare that there is no conflict of interests regarding the publication of this paper.

\section{References}

[1] J. D. Navratil and A. E. Stewart, "Waste treatment using molten salt oxidation," Nukleonika, vol. 41, no. 4, pp. 57-72, 1996.

[2] H. G. MacPherson, “The molten salt adventure," Nuclear Science and Engineering, vol. 90, no. 4, pp. 374-380, 1985.

[3] S. J. Yosim and K. M. Barclay, "Gasification of waste using molten-salts," Abstracts of papers of the American Chemical Society: 10-10, Supplement I, 1976.

[4] L. G. Morgan, L. L. Burger, and R. D. Scheele, "Molten-salt oxidation-reduction processes for fuel processing," Abstracts of Papers of the American Chemical Society (APR): 127-127, 1979.

[5] L. W. Gray, M. G. Adamson, J. F. Cooper, J. C. Farmer, and R. S. Upadhye, "Molten-salt oxidation as an alternative to incineration," in Proceedings of the Incineration Conference on Thermal Treatment of Radioactive, Hazardous Chemical, Mixed and Medical Wastes, M. E. Wacks, Ed., pp.151-155, Albuquerque, NM, USA, May 1992.

[6] D. Stelman, A. E. Stewart, S. J. Yosim, and R. L. Gay, “Treatment of mixed wastes by the molten-salt oxidation process," in Proceedings of the Incineration Conference: Thermal Treatment of Radioactive, Hazardous Chemical, Mixed and Medical Wastes, M. E. Wacks, Ed., Albuquerque, NM, USA, May 1992.

[7] Technology Needs Assessment, Evaluation of the Molten Salt Oxidation Process Technology, Chem-Nuclear Geotech, Grand Junction, Colo, USA, 1992.

[8] J. D. Navratil, "Molten-salt oxidation of mixed wastes," Abstracts of Papers of the American Chemical Society 205: 295CHED, Part 1, 1993.

[9] J. T. Bell, P. A. Haas, and J. C. Rudolph, "Molten salt oxidation of mixed wastes: separation of radioactive materials and resource conservation and recovery act (RCRA) materials," Separation Science and Technology, vol. 30, no. 7-9, pp. 1755-1767, 1995, Proceedings of the 8th Symposium on Separation Science and Technology for Energy Applications, Gatlinburg, Tenn, USA, October 1993.

[10] S. M. Crosley, D. K. Lorenzo, J. E. van Cleve et al., "Treatment of waste by the molten salt oxidation process at the Oak Ridge National Laboratory, environmental remediation and environmental issues," in Proceedings of the 1993 International Conference on Nuclear Waste Management and Environmental Remediation, September 1993.

[11] J. J. Cudahy, "Technical review of molten salt oxidation," DOE/EM-0139P, 1993.

[12] J. D. Navratil, "Processing of spent salt from the moltensalt oxidation of hazardous and radioactive-wastes. Actinide processing: methods and materials: 267-273," in Proceedings of the the 123rd Annual Meeting of the Minerals-Metals-andMaterials-Society: International Symposium on Actinide Processing: Methods and Materials, B. Mishra and W. A. Averill, Eds., San Francisco, Calif, USA, February-March 1994.

[13] P. A. Haas, J. C. Rudolph, and J. T. Bell, "Molten salt oxidation of mixed wastes: preliminary bench-scale experiments without radioactivity," ORNL/TM 12765, Oak Ridge National Laboratory, 1994.

[14] M. G. Adamson and R. D. Streit, "The mixed waste management facility: a DOE technology demonstration project," UCRL-JC117306, 1994.

[15] A. E. Bogner, P. Cherish, and S. T. Schamp, "High temperature liquid injection apparatus,” US Patent 5,346,133, 1994.

[16] R. A. VanKonynenburg, R. W. Hopper, J. A. Rard et al., "Ceramic waste form for residues from molten salt oxidation of mixed wastes," in Proceedings of the 19th Symposium on Scientific Basis for Nuclear Waste Management, at the 1995 MRS Fall Meeting, W. M. Murphy and D. A. Knecht, Eds., vol. 412, pp. 321-328, Boston, Mass, USA, November-December 1995.

[17] J. D. Navratil, M. J. Wolters, J. R. Rohlfs, A. E. Stewart, and R. J. Ayen, "Update on molten salt oxidation of mixed wastes," in Proceedings of the 3rd Biennial Symposium on Mixed Waste in Baltimore, A. A. Moghissi, B. R. Love, and R. K. Blauvelt, Eds., pp. 423-432, Baltimore, Md, USA, Augast 1995.

[18] R. L. Gay, D. L. Grimmett, and J. C. Newcomb, "Advances in molten salt oxidation at ETEC", in Proceedings of the $3 r d$ Biennial Symposium on Mixed Waste, A. A. Moghissi, B. R. Love, and R. K. Blauvelt, Eds., pp. 433-439, Baltimore, Md, USA, August 1995.

[19] P. R. Lageraaen, P. D. Kalb, D. L. Grimmett, R. L. Gay, and C. D. Newman, "Polyethylene encapsulation of molten salt oxidation mixed low-level radioactive salt residues," in Proceedings of the 3rd Biennial Symposium on Mixed Waste, A. A. Moghissi, B. R. Love, and R. K. Blauvelt, Eds., Baltimore, Md, USA, August 1995.

[20] D. R. Sadoway, "New opportunities for metals extraction and waste treatment by electrochemical processing in molten salts," Journal of Materials Research, vol. 10, no. 3, pp. 487-492, 1995.

[21] R. L. Gay, "Molten salt vessel," US Patent 5,398,914, 1995.

[22] W. A. Bummond and R. S. Upadye, "Injector nozzle for molten salt destruction of energetic waste materials," US Patent 5,491,280, 1996.

[23] P. C. Hsu, L. J. Summers, E. H. von Holtz, W. A. Brummond, F. T. Wang, and M. G. Adamson, "MSO spent salt clean-up/recovery process," UCRL-ID-126437, 1997.

[24] R. A. van Konynenburg, R. W. Hopper, J. A. Rard et al., "Ceramic waste form for residues from molten salt oxidation of mixed wastes," Materials Research Society Symposium Proceedings, vol. 412, 1996.

[25] M. G. Adamson, B. B. Ebbinghaus, and P. C. Hsu, “Thermodynamics of metal volatility and speciation in the molten salt oxidation of organic-based radioactive wastes," in Proceedings of the 9th International Conference on High Temperature Materials Chemistry (HTMC'97), K. E. Spear, Ed., pp. 276-277, University Park, Pa, USA, May 1997.

[26] P. C. Hsu, "Integrated demonstration of molten salt oxidation with salt recycle for mixed waste treatment," Tech. Rep. UCRLJC-128143, Lawrence Livermore National Lab, 1997.

[27] L. Summers, P. C. Hsu, E. V. Holtz, D. Hipple, F. Wang, and M. Adamson, "Removal of uranium from spent salt from the molten salt oxidation process," UCRL-ID-126857, 1997. 
[28] M. G. Adamson, D. L. Hipple, R. W. Hopper, and P. C. Hsu, "FY98 final report for the expedited technology demonstration project: demonstration test results for the integrated MSO waste treatment system," Tech. Rep. UCRL-ID-133534, 1998.

[29] P. D. Ferro, B. Mishra, D. L. Olson, and W. A. Averill, "Application of ceramic membrane in molten salt electrolysis of CaO$\mathrm{CaCl}_{2}$," Waste Management, vol. 17, no. 7, pp. 451-461, 1998.

[30] Z. R. Ismagilov, M. A. Kerzhentsev, R. A. Shkrabina et al., "A role of catalysis for the destruction of waste from the nuclear industry," Catalysis Today, vol. 55, no. 1-2, pp. 23-43, 2000, Proceedings of the 2nd World Congress of Environmental Catalysis, Miami, Fla, USA, November 1998.

[31] M. A. Kerzhentsev, M. G. Adamson, Z. R. Ismagilov, and Y. S. Chekryshkin, "Oxidation of organic compounds and carbon monoxide in some molten salts and catalysts," in Proceedings of the European Research Conference on Advances in Molten SaltsFrom Structural Aspect to Waste Processing, M. Gaune-Escard, Ed., pp. 279-299, Porquerolles Island, France, June 1998.

[32] M. G. Adamson, P. C. Hsu, D. L. Hipple, K. G. Foster, R. W. Hopper, and T. D. Ford, "Organic waste processing using molten salt oxidation," in Advances in Molten Salts: From Structural Aspects to Waste Processing: Proceedings of the European Research Conference on Molten Salts, June 27-July 3, 1998, Porqueerolles, M. Gaune-Escard, Ed., 1998.

[33] B. A. A. L. van Setten, J. Bremmer, S. J. Jelles, M. Makkee, and J. A. Moulijn, "Ceramic foam as a potential molten salt oxidation catalyst support in the removal of soot from diesel exhaust gas," Catalysis Today, vol. 53, no. 4, pp. 613-621, 1999.

[34] M. G. Adamson, P. C. Hsu, D. L. Hippie, K. G. Foster, R. W. Hopper, and T. D. Ford, "Organic waste processing using molten salt oxidation," High Temperature Material Processes, vol. 2, no. 4, pp. 559-580, 1998.

[35] M. Alam and S. Kamath, "Cyanide destruction in molten carbonate bath: melt and gas analyses," Environmental Science \& Technology, vol. 32, no. 24, pp. 3986-3992, 1998.

[36] K. B. Ramsey, E. M. Foltyn, and J. M. Heslop, “Overview of advanced technologies for stabilization of Pu-238contaminated waste," in Space Technology and Applications International Forum-1998, Parts 1-3-1st Conference on Global Virtual Presence; 1st Conference on Orbital Transfer Vehicles; 2nd Conference on Applications of Thermophysics in Microgravity; 3rd Conference on Commercial Development of Space; 3rd Conference on Next Generation Launch System; 15th Symposium on Space Nuclear Power and Propulsion, M. S. El-Genk, Ed., Space Technology and Applications International Forum (STAIF-98) - Progress in Expanding the Space Frontier in Albuquerque, NM, January 1998, no. 420, pp. 1314-1320, 1998.

[37] P. C. Hsu, D. L. Hipple, D. V. Squire et al., "Molten salt oxidation for hazardous waste treatment," Abstracts of Papers of the American Chemical Society 216:125-IEC, Part 1, 1998.

[38] P. C. Hsu, D. L. Hipple, K. G. Foster, T. D. Ford, R. W. Hopper, and M. G. Adamson, "Molten salt oxidation for treating lowlevel mixed wastes," Waste Treatment 99, Lawrence Livermore National Laboratory, Tucson, Ariz, USA, 1998.

[39] R. Wishau, A. Montoya, and K. B. Ramsey, "Application of molten salt oxidation for the minimization and recovery of $\mathrm{Pu}$-238-contaminated wastes," in Creation and Future Legacy of Stockpile Stewardship: Isotope Production, Applications, and Consumption: Proceedings of the 32nd Midyear Topical Meeting, 24-27 January 1999, Albuquerque, New Mexico, J. M. Hylko and R. L. Salyer, Eds., pp. 175-179, 1999.
[40] P. C. Hsu, T. Ford, K. Foster et al., "Molten salt oxidation for the treatment of spent activated carbon," Abstracts of Papers of the American Chemical Society 218: 107-IEC, part 1, 1999.

[41] J. Johnson and J. Winnick, "Electrochemical membrane separation of chlorine from gaseous hydrogen chloride waste," Separation and Purification Technology, vol. 15, no. 3, pp. 223229, 1999.

[42] J. Stimmel, R. Wishau, K. B. Ramsey, A. Montoya, J. Brock, and M. Heslop, "Treatment of plutonium process residues by molten salt oxidation," in Proceedings of the Waste Management '99 symposium (WM '99), Tucson, Ariz, USA, February-March 1999.

[43] A. Sheth, P. Agrawal, and Y. D. Yeboah, "Catalytic gasification of coal using eutectic salt mixtures," DOE Report, 1999.

[44] P. C. Hsu and M. G. Adamson, "Final report for the expedited technology demonstration project: demonstration test results for the MSO/off-gas and salt recycle system," Tech. Rep. UCRLID-134688, 1999.

[45] P. C. Hsu, K. G. Foster, T. D. Ford et al., "Treatment of solid wastes with molten salt oxidation," Waste Management, vol. 20, no. 5-6, pp. 363-368, 2000.

[46] D. Lexa, L. Leibowitz, A. J. Kropf, and I. Johnson, "Interaction of molten chloride salts and zeolite $4 \mathrm{~A}$-nature, thermodynamics, and application to nuclear waste treatment and disposal," in High Temperature Materials Chemistry, Parts I and II, Proceedings, vol. 15, part 1, pp. 31-34, 2000, presented at 10th International Conference of the International-Union-of-Pureand-Applied-Chemistry in Julich, Germany, April 10-14, 2000.

[47] M. L. Remerowski, J. J. Stimmel, A. S. Wong, and K. B. Ramsey, "Pu-238 recovery and salt disposition from the molten salt oxidation process," in Plutonium Futures-The Science, K. K. S. Pillay and K. C. Kim, Eds., vol. 532, pp. 246-247, 2000, Presented at Topical Conference on Plutonium and Actinides in Santa Fe, NM, July 10-13, 2000.

[48] J. J. Stimmel, M. L. Remerowski, K. B. Ramsey, and J. M. Heslop, "Stabilization of $\mathrm{Pu}$-238-contaminated combustible waste by molten salt oxidation," in Plutonium Futures-The Science, K. K. S. Pillay and K. C. Kim, Eds., vol. 532, pp. 248-249, 2000, Presented at Topical Conference on Plutonium and Actinides in Santa Fe, NM, USA, July 10-13, 2000.

[49] Y. J. Shin, I. S. Kim, S. C. Oh, C. K. Park, and C. S. Lee, "Lithium recovery from radioactive molten salt wastes by electrolysis," Journal of Radioanalytical and Nuclear Chemistry, vol. 243, no. 3, pp. 639-643, 2000.

[50] A. E. Stewart, "Treatment of pulp mill liquors using molten alkaline salt," in Proceedings of the AIChE Forest Products Division Technical Program, Session 318. Paper 318d, 2000.

[51] B. Mishra, "Recovery and utilization of reactive metals by molten salt electrochemistry," in Proceedings of the 4th International Conference on Materials Engineering for Resources, vol. 1, pp. 7-12, Akita, Japan, October 2001.

[52] T. R. Griffiths, S. Barr, V. A. Volkovich, and E. M. Anghel, "Destruction of organic wastes using molten carbonates," in Proceedings of the 6th International Symposium on Molten Salt Chemistry and Technology, C. Nianyi and Q. Zhiyu, Eds., pp. 130-135, Shanghai, China, October 2001.

[53] D. J. Fray, "Emerging molten salt technologies for metals production," Journal of Metals, vol. 53, no. 10, pp. 26-31, 2001.

[54] P. C. Hsu, B. Watkins, C. Pruneda, and S. Kwak, "Molten salt oxidation: a thermal technology for waste treatment and demilitarization," Tech. Rep. UCRL-JC-142013, Lawrence Livermore National Lab, 2001. 
[55] P. C. Hsu and M. G. Adamson, Molten Salt Oxidation, CRC Press, 2001.

[56] S. Pandeti, Thermal treatment of chlorobenzene using molten salt oxidation [M.S. thesis], University of Maryland, College Park, Md, USA, 2002.

[57] B. Mishra and D. L. Olson, "Production of reactive metals by molten salt processing," in Molten Salts XIII, P. C. Trulove, H. C. DeLong, R. A. Mantz, G. R. Stafford, and M. Matsunaga, Eds., vol. 19, pp. 758-770, 2002, presented at 13th International Symposium on Molten Salts in Philadelphia, Pa, USA, May 1217, 2002.

[58] T. R. Griffiths, V. A. Volkovich, and E. M. Anghel, "Molten salt oxidation: a reassessment of its supposed catalytic mechanism and hence its development for the disposal of waste automotive tires," in Molten Salts XIII, P. C. Trulove, H. C. DeLong, R. A. Mantz, G. R. Stafford, and M. Matsunaga, Eds., vol. 19, pp. 306317,2002 , Presented at 13th International Symposium on Molten Salts in Philadelphia, Pa, USA, May 12-17, 2002.

[59] W. Smith and F. Feizollahi, "Thermal destruction of highly chlorinated mixed wastes without generating corrosive offgases using molten salt oxidation $(1,2)$," in Proceedings of the Waste Management Conference, February 2002.

[60] P. C. Hsu, E. H. von Holtz, D. L. Hipple, L. J. Summers, and M. G. Adamson, "Actinide removal from spent salts," US Patent no. 6,471,922 B1, 2002.

[61] W. A. Brummond, D. V. Squire, J. A. Robinson, and P. A. House, "Delivery System for Molten Salt Oxidation of Solid Waste," US Patent 6,489,532 B1, 2002.

[62] V. M. B. Nunes, M. J. V. Lourenco, F. J. V. Santos, and C. A. N. de Castro, "Importance of accurate data on viscosity and thermal conductivity in molten salts applications," Journal of Chemical and Engineering Data, vol. 48, no. 3, pp. 446-450, 2002, presented at IUPAC Workshop on Ionic Liquids in Rostock, Germany, July-August.

[63] B. Mishra, "Application of molten salts in metals production," in Proceedings of the Yazawa International Symposium: Metallurgical and Materials Processing: Principles and Technologies, F. Kongoli, K. Itagaki, C. Yamauchi, and H. Y. Sohn, Eds., pp. 579593, San Diego, Calif, USA, March 2003.

[64] H. C. Yang, Y. J. Cho, J. S. Yun, and J. H. Kim, "Destruction of halogenated plastics in a molten salt oxidation reactor," The Canadian Journal of Chemical Engineering, vol. 81, no. 3-4, pp. 713-718, 2003.

[65] P. C. Hsu and S. Kwak, Treatment of Difficult Wastes with Molten Salt Oxidation, Lawrence Livermore National Laboratory, 2003.

[66] H.-C. Yang, Y.-J. Cho, H.-C. Eun, J.-H. Yoo, and J.-H. Kim, "Behavior of toxic metals and radionuclides during molten salt oxidation of chlorinated plastics," Journal of Environmental Science and Health-Part A Toxic/Hazardous Substances and Environmental Engineering, vol. 39, no. 6, pp. 1601-1616, 2004.

[67] S. Pandeti and S. G. Buckley, "Molten salt oxidation of chlorobenzene," Combustion Science and Technology, vol. 176, no. 2, pp. 257-276, 2004.

[68] M. L. Remerowski, C. Dozhier, K. Krenek et al., "Recovery of $\mathrm{Pu}-238$ by molten salt oxidation processing of $\mathrm{Pu}-238$ contaminated combustibles," in Proceedings of the AIChE Spring National Meeting, April 2004.

[69] T. Tzvetkoff and J. Kolchakov, "Mechanism of growth, composition and structure of oxide films formed on ferrous alloys in molten salt electrolytes-a review," Materials Chemistry and Physics, vol. 87, no. 1, pp. 201-211, 2004.
[70] Y.-J. Cho, H.-C. Yang, H.-C. Eun, J.-H. Yoo, and J.-H. Kim, "Axial gas phase dispersion in a molten salt oxidation reactor," Korean Journal of Chemical Engineering, vol. 21, no. 6, pp. 12501255, 2004.

[71] "Short review. Destruction of chlorinated organic solvents in a molten carbonate with transition metal oxides," in Predisposal Management of Organic Radioactive Waste, IAEA Technical Reports Series 427, pp. 52-53, International Atomic Energy Agency, 2004.

[72] H. C. Yang, Y. J. Cho, H. C. Eun, J. H. Kim, and Y. Kang, "New developments and application in chemical reaction engineering," in Proceedings of the 4th Asia-Pacific Chemical Reaction Engineering Symposium (APCRE '05), H.-K. Rhee, I.-S. Nam, and J. M. Park, Eds., Gyeongju, Republic of Korea, June 2005.

[73] H. C. Yang, Y. J. Cho, H. C. Eun, J. H. Kim, and Y. Kang, "Destruction of chlorinated organic solvents in a molten carbonate with transition metal oxides," Studies in Surface Science and Catalysis, vol. 159, pp. 577-580, 2006.

[74] H.-C. Yang, Y.-J. Cho, H.-C. Eun, J.-H. Yoo, and J.-H. Kim, "Molten salt oxidation of ion-exchange resins doped with toxic metals and radioactive metal surrogates," Journal of Nuclear Science and Technology, vol. 42, no. 1, pp. 123-129, 2005.

[75] M. L. Remerowski, C. Dozhier, K. Krenek et al., "Recovery of ${ }^{238} \mathrm{PuO}_{2}$ by molten salt oxidation processing of ${ }^{238} \mathrm{PuO}_{2}$ contaminated combustibles (part II)," AIP Conference Proceedings, vol. 746, pp. 806-814, 2005.

[76] Y.-J. Cho, H.-C. Yang, H.-C. Eun, J.-H. Yoo, and J.-H. Kim, "Hydrodynamic and gas phase axial dispersion in an air-molten salt two-phase system (molten salt oxidation reactor)," Chemical Engineering and Processing: Process Intensification, vol. 44, no. 10, pp. 1054-1062, 2005.

[77] G. Jin, H. Iwaki, N. Arai, and K. Kitagawa, "Study on the gasification of wastepaper/carbon dioxide catalyzed by molten carbonate salts," Energy, vol. 30, no. 7, pp. 1192-1203, 2005.

[78] D. J. Hebditch, M. T. Harrison, R. E. Streatfield, and C. E. Stephen, "Applicability of high temperature processes for the treatment of a wide range of Magnox reactor wastes," in Proceedings of the 10th International Conference on Environmental Remediation and Radioactive Waste Management (ICEM '05), pp. 601-608, Glasgow, UK, September 2005.

[79] M. G. Adamson, Z. Chiba, E. H. von Holtz, and R. D. Streit, "Development of advanced waste treatment technologies for demonstration in the mixed waste treatment facility," in Proceedings of the 3rd Biennial Mixed Waste Symposium, Baltimore, Md, USA, 1995.

[80] J. D. Navratil, "Development of new non-thermal destruction methods for organic components of radioactive waste," in Proceedings of the 3rd Research Coordination Meeting of the International Atomic Energy Agency Project, New Developments and Improvements in Processing of Problematic Radioactive Waste Streams, Mumbai, India, November-December 2006.

[81] S. Shimano and S. Asakura, "The redox combustion of carbon monoxide for recovering pure carbon dioxide by using molten salt mixtures," Chemosphere, vol. 63, no. 10, pp. 1641-1647, 2006.

[82] T. R. Griffiths, V. A. Volkovich, E. M. Anghel, and W. R. Carper, "Molten salt oxidation for the efficient destruction of radioactive, hazardous chemical, medical waste and munitions," in Proceedings of the 24th International Conference on Incineration and Thermal Treatment Technologies, pp. 1-10, Galveston, Tex, USA, May 2005.

[83] Y.-J. Cho, H.-C. Yang, H.-C. Eun, E.-H. Kim, and I.-T. Kim, "Characteristics of oxidation reaction of rare-earth chlorides 
for precipitation in LiCl-KCl molten salt by oxygen sparging," Journal of Nuclear Science and Technology, vol. 43, no. 10, pp. 1280-1286, 2006.

[84] T. Carlson, C. Carpenter, and L. Cummins, "Mixed waste treatment-what about the residuals?" Tech. Rep. GJPO-M-03093, U.S. Department of Energy, Grand Junction Projects Office, 1993.

[85] C. S. Seo, B. H. Park, S. B. Park, K.-J. Jung, S. W. Park, and S. H. Kim, "Study on the characteristics of the ion exchange of zeolite $4 \mathrm{~A}$ in a molten $\mathrm{LiCl}$ system," Journal of Chemical Engineering of Japan, vol. 39, no. 1, pp. 27-33, 2006.

[86] H. C. Yang, Y. J. Cho, H. C. Eun et al., "Destruction of chlorinated organic solvents in a molten carbonate with transition metal oxides. New developments and application in chemical reaction engineering," in Proceedings of the 4th AsiaPacific Chemical Reaction Engineering Symposium (APCRE '05), Gyeongju, Korea, June 2005, Studies in Surface Science and Catalysis, vol. 159, pp. 577-580, 2006.

[87] International Atomic Energy Agency, Application of Thermal Technologies for Processing of Radioactive Waste, IAEA-Tecdoc1527, IAEA, 2006.

[88] H.-S. Park, I.-T. Kim, Y.-Z. Cho, H.-C. Eun, and J.-H. Kim, "Characteristics of solidified products containing radioactive molten salt waste," Environmental Science \& Technology, vol. 41, no. 21, pp. 7536-7542, 2007.

[89] K. Sugiura, K. Minami, M. Yamauchi, S. Morimitsu, and K. Tanimoto, "Gasification characteristics of organic waste by molten salt," Journal of Power Sources, vol. 171, no. 1, pp. 228236, 2007.

[90] H. C. Yang, Y. J. Cho, H. C. Eun, and E. H. Kim, "Destruction of chlorinated organic solvents in a two-stage molten salt oxidation reactor system," Chemical Engineering Science, vol. 62, no. 18-20, pp. 5137-5143, 2007.

[91] "Environmental remediation and radioactive waste management, parts A and B," in Proceedings of the 11th International Conference on Environmental Remediation and Radioactive Waste Management, pp. 315-319, Bruges, Belgium, September 2007.

[92] H.-C. Yang, Y.-J. Cho, H.-C. Eun, and E.-H. Kim, "Destruction of chlorinated organic solvents in a two-stage molten salt oxidation reactor system," Chemical Engineering Science, vol. 62, no. 18-20, pp. 5137-5143, 2007.

[93] S. Kunze, "Development of decontaminating agents to their present status or detergents for decontamination work in the nuclear field," ATW-International Journal for Nuclear Power, vol. 52, no. 6, p. 429, 2007.

[94] P. E. O. Lainetti and A. Abrao, "Thermal decomposition of contaminated organic solutions using molten salt oxidationpreliminary developments," in Proceedings of the International Nuclear Atlantic Conference (INAC '07), 2007.

[95] H. C. Yang, Y. Z. Cho, H. C. Eun, and Y. Kang, "Destruction of trichloroethylene in a two stage molten salt oxidation reactor system," Journal of Chemical Engineering of Japan, vol. 41, no. 7, pp. 597-601, 2008.

[96] H. C. Yang, Y. J. Cho, H. C. Eun, and E. H. Kim, "Destruction of chlorobenzene and carbon tetrachloride in a two-stage molten salt oxidation reactor system," Chemosphere, vol. 73, no. 1, supplement, pp. S311-S315, 2008.

[97] H.-S. Park, I.-T. Kim, Y.-Z. Cho, H.-C. Eun, and H.-S. Lee, "Stabilization/solidification of radioactive salt waste by using $x \mathrm{SiO}_{2}-y \mathrm{Al}_{2} \mathrm{O}_{3}-z \mathrm{P}_{2} \mathrm{O}_{5}$ (SAP) material at molten salt state," Environmental Science and Technology, vol. 42, no. 24, pp. 93579362, 2008.

[98] T. R. Griffiths and V. A. Volkovich, "A new technology for the nuclear industry for the complete and continuous pyrochemical reprocessing of spent nuclear fuel: catalyst enhanced molten salt oxidation," Nuclear Technology, vol. 163, no. 3, pp. 382-400, 2008, presented at Symposium on Molten Salt Chemistry and Technology in Toulouse, France, August 2005.

[99] P. Sachdev, M. F. Simpson, S. M. Frank, K. Yano, and V. Utgikar, "Selective separation of Cs and Sr from LiCl-based salt for electrochemical processing of oxide spent nuclear fuel," Separation Science and Technology, vol. 43, no. 9-10, pp. 27092721, 2008, Proceedings of the 15th Symposium on Separation Science and Technology for Energy Applications, Gatlinburg, Tenn, USA, October 2007.

[100] O. Takeda, T. Handa, M. Kimura, Y. Yokka, and Y. Sato, "Decomposition process for polychlorobiphenyl containing 1 to 5 chlorine by using basic molten salts as reaction field," in Proceedings of the Extraction and Processing Division (EPD '08), S. M. Howard, Ed., pp. 503-508, New Orleans, LA, USA, March 2008.

[101] K.-W. Kim, I.-T. K. G.-I. Park, H.-S. Park, E.-H. Lee, and E.H. Kim, "Electrochemical de-chlorination/transformation of metal chloride for the preparation of NZP structure product," Journal of Radioanalytical and Nuclear Chemistry, vol. 275, no. 3, pp. 595-604, 2008.

[102] K. R. Kim, J. D. Bae, B. G. Park et al., "Modeling and analysis of a molten-salt electrolytic process for nuclear waste treatment," Journal of Radioanalytical and Nuclear Chemistry, vol. 280, no. 2, pp. 401-404, 2009, presented at 2nd International Nuclear Chemistry Congress (2nd-INCC) in Cancun, Mexico, April 1317, 2008.

[103] Y.-Z. Cho, H.-C. Yang, G.-H. Park, H.-S. Lee, and I.-T. Kim, "Treatment of a waste salt delivered from an electrorefining process by an oxidative precipitation of the rare earth elements," Journal of Nuclear Materials, vol. 384, no. 3, pp. 256-261, 2009.

[104] Y.-Z. Cho, G.-H. Park, H.-C. Yang, D.-S. Han, H.-S. Lee, and I.T. Kim, "Minimization of eutectic salt waste from pyroprocessing by oxidative precipitation of lanthanides," Journal of Nuclear Science and Technology, vol. 46, no. 10, pp. 1004-1011, 2009.

[105] Y.-Z. Cho, H.-C. Yang, and Y. Kang, “Two phase (air-molten carbonate salt) flow characteristics in a molten salt oxidation reactor," Korean Journal of Chemical Engineering, vol. 26, no. 3, pp. 828-832, 2009.

[106] K. R. Kim, J. D. Bae, and B. G. Park, "Modeling and analysis of a molten-salt electrolytic process for nuclear waste treatment," Journal of Radioanalytical and Nuclear Chemistry, vol. 280, no. 2, pp. 401-404, 2009, Presented at 2nd International Nuclear Chemistry Congress (INCC’ 08) in Cancún, Mexico, April 1317, 2008.

[107] K. R. Kim, S. Y. Choi, J. G. Kim et al., "Multi physics modeling of a molten-salt electrolytic process for nuclear waste treatment," Actinides, vol. 9, no. 1, Article ID 012002, 2009.

[108] I. T. Kim, H. S. Park, Y. Z. Cho, K. W. Kim, S. W. Park, and E. H. Kim, "Characteristics of solidified products containing radioactive molten salt waste," in Proceedings of the 11th International Conference on Environmental Remediation and Radioactive Waste Management, Parts A and B (ICEM '07), pp. 315-319, Bruges, Belgium, September 2007.

[109] P. Taxil, L. Massot, C. Nourry, M. Gibilaro, P. Chamelot, and L. Cassayre, "Lanthanides extraction processes in molten fluoride 
media: application to nuclear spent fuel reprocessing," Journal of Fluorine Chemistry, vol. 130, no. 1, pp. 94-101, 2009.

[110] C. Billings, "Process for production of hydrogen from coal and other fossil fuels," Article ID 20090074656, U.S. Patent Application 20090074656, filed September 2008, and issued March 2009.

[111] Environment Australia, "Molten media processes," Review Report 4, Environment Australia, 1997.

[112] T. R. Griffiths, V. A. Volkovich, and W. R. Carper, "The structures of the active intermediates in catalyst-enhanced molten salt oxidation and a new method for the complete destruction of chemical warfare arsenicals," Structural Chemistry, vol. 21, no. 2, pp. 291-297, 2010.

[113] H. C. Yang, Y. J. Chu, H. C. Eun, and K. W. Lee, "Optimization of a molten carbonate reactor system for a destruction of spent cationic ion-exchange resins," in Proceedings of the 13th International Conference on Process Integration, Modeling and Optimization for Energy Saving and Pollution Reduction, J. J. Klemes, H. L. Lam, and P. S. Varbanov, Eds., vol. 21, pp. 889894, Prague, Czech Republic, August-September 2010.

[114] X. Y. Zhao, Z. T. Yao, and J. H. Li, "Study on the properties and applications of molten salts," in Proceedings of the 5th International Conference on Waste Management and Technology (ICWMT '10), J. H. Li and H. L. Hu, Eds., vol. 5, pp. 125-128, Beijing, China, December 2010.

[115] K. R. Kim, S. Y. Choi, J. G. Kim et al., "Multi physics modeling of a molten-salt electrolytic process for nuclear waste treatment," Actinides 2009, vol. 9, no. 1, Article ID 012002, 2009, edited by L. Rao; J. G. Tobin; D. K. Shuh, presented at Actinides Conference in San Francisco, Calif, USA, July 12-17, 2009. Book series title: IOP Conference Series-Materials Science and Engineering.

[116] Z. Yao, J. Li, and X. Zhao, "Molten salt oxidation: a versatile and promising technology for the destruction of organic-containing wastes," Chemosphere, vol. 84, no. 9, pp. 1167-1174, 2011.

[117] B.-G. Ahn, H.-S. Park, I.-T. Kim, and H.-S. Lee, "Solidification of Ln oxides containing volatile chlorides from pyrochemical process," Nuclear Technology, vol. 173, no. 3, pp. 300-309, 2011.

[118] P. E. O. Lainetti, "Molten salt oxidation-a safe process for hazardous organic wastes decomposition," in Proceedings of the Cleaner Production Initiatives and Challenges for a Sustainable World, São Paulo, Brazil, May 2011.

[119] P. C. Hsu and S. Kwak, "Treatment of difficult wastes with molten salt oxidation," in Proceedings of the 20th Joint ArmyNavy-NASA-Air Force (JANNAF) Safety and Environmental Protection Subcommittee (SEPS), p. 14, Charlottesville, Va, USA, 2003.

[120] W. Smith and F. Feizollahi, "Thermal destruction of highly chlorinated mixed wastes without generating corrosive offgases using molten salt oxidation," in Proceedings of the WM'02 Conference, p. 15, Tucson, Ariz, USA, February 2002.

[121] T. Rivers, "Waste treatment using molten salt oxidation technology," in Proceedings of the 15th Annual Global Demilitarization Symposium \& Exhibition, Reno, Nev, USA, May 2007.

[122] A. J. Darnell, R. L. Gay, J. D. Navratil, and J. C. Newcomb, "Molten salt oxidation of radioactive hydraulic oil waste," in Proceedings of the 2nd International Symposium on Mixed Waste, American Society of Mechanical Engineers, Baltimore, Md, USA, 1993. 


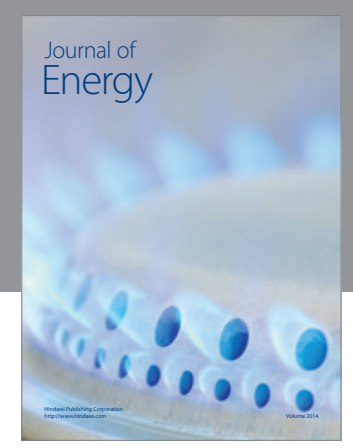

Journal of

Industrial Engineering
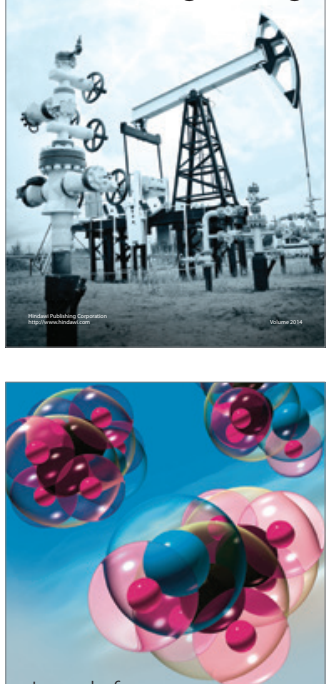

Fuels
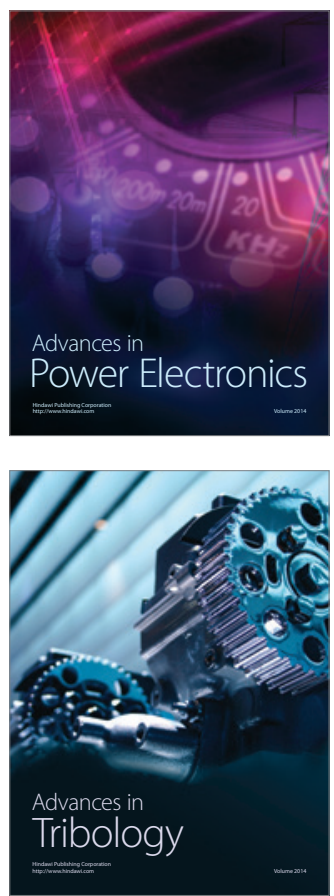

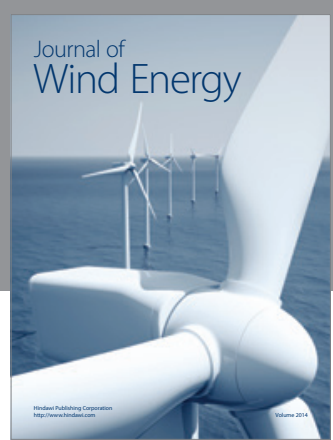

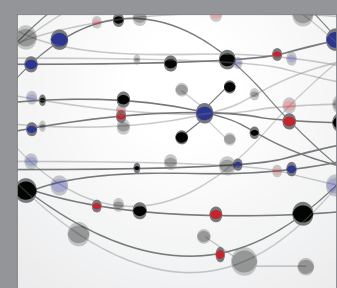

The Scientific World Journal

Submit your manuscripts at http://www.hindawi.com

Journal of

Structures
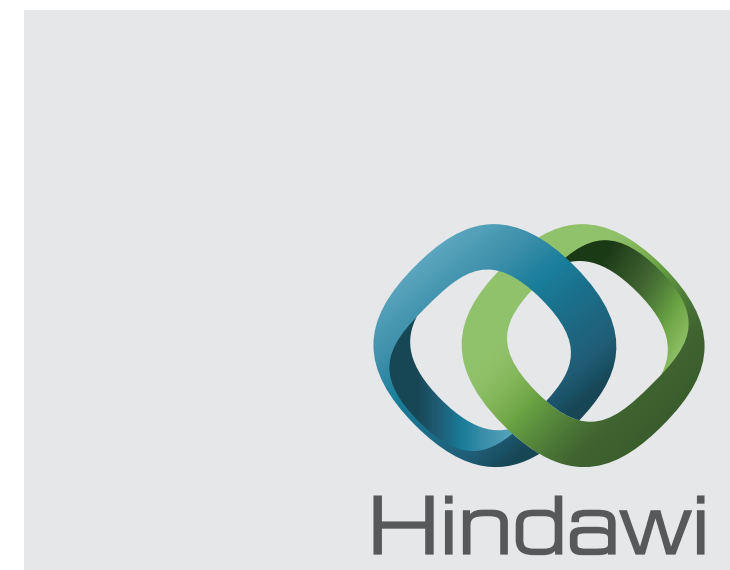

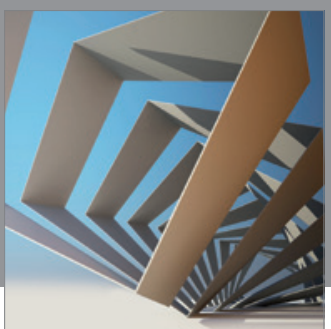

Rotating

Machinery
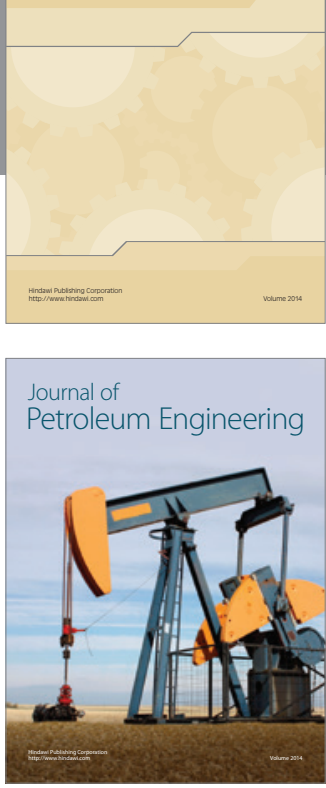

Journal of

Solar Energy
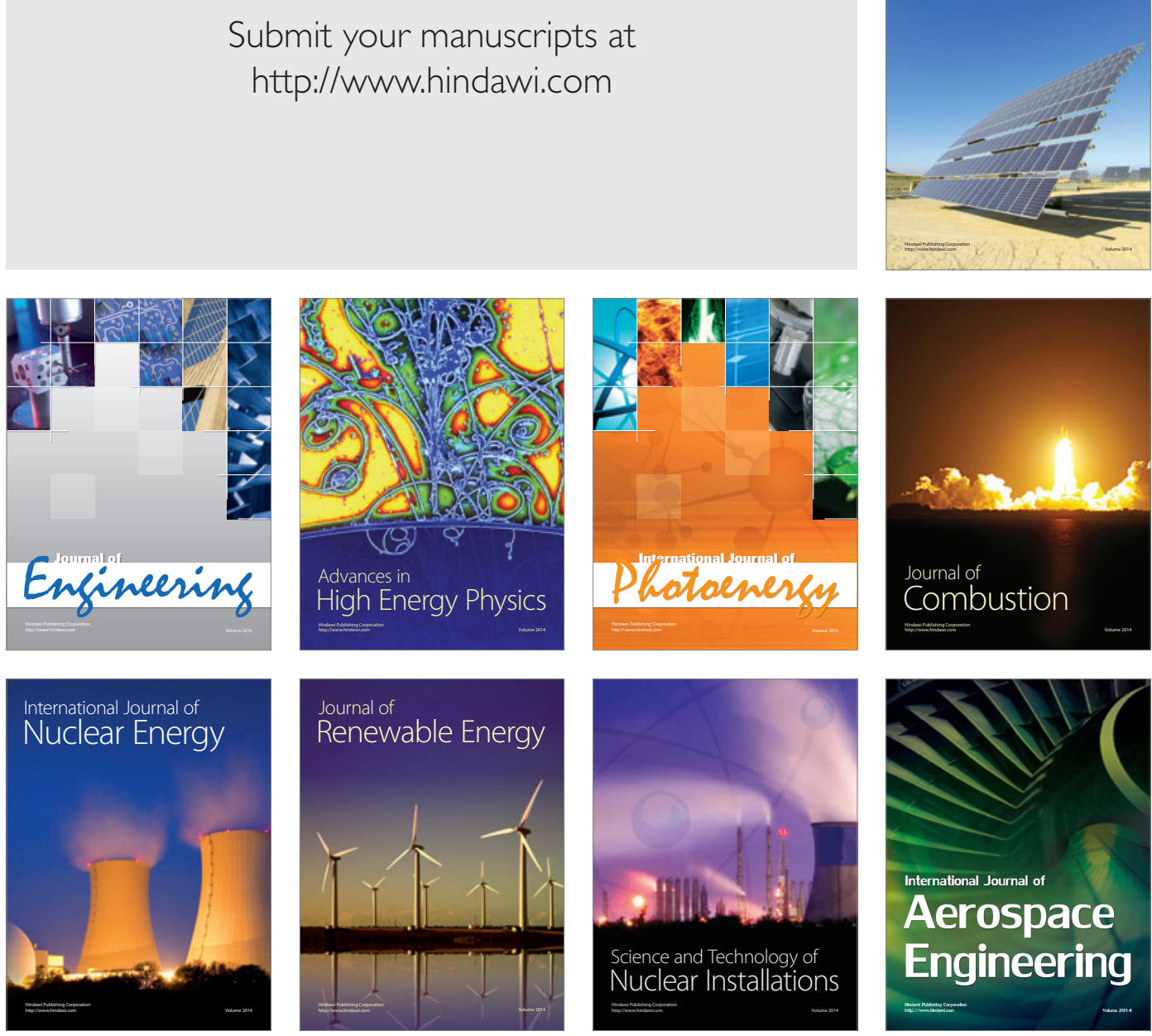